American Journal of Economics and Business Administration 2 (1): 113-119, 2010

ISSN 1945-5488

(C) 2010 Science Publications

\title{
Clayboy Pottery Company: A Case Study in Quality Management in a Job Shop Operations System
}

\author{
Michael R. Summers \\ Business Administration Division, Pepperdine University, Malibu, CA 90263
}

\begin{abstract}
Background: This case study is designed for upper-level undergraduate students in a basic operations management course. Prerequisites would include statistics and computer science. Objective: The purpose of the case is to give the students an opportunity to apply statistical quality control techniques. The case presents an interesting problem in a real setting and students will be forced to consider realistic issues in tradeoffs between cost and quality. The setting is a job shop, where jobs arrive randomly and have different requirements, as opposed to a mass-production type of system. Methodology: The analysis lends itself nicely to working on spreadsheets and the data may be changed easily to provide for reuse of the case. Based on probability calculations of the number of defects found in a group of current jobs, students calculate the costs of various sampling techniques. Results: Students are expected to try different sampling alternatives in order to minimize costs and also to consider nonquantitative ramifications of different alternatives and the realities of the situation. Conclusion: From this case study students should develop a good appreciation of statistical quality control techniques, as well as other aspects of a total quality management program.
\end{abstract}

Key words: Operations management, statistical quality control, case studies

\section{INTRODUCTION}

Linda and Doug Rice are the founders and owners of the Clayboy Pottery Company. While an art major at the University of California at Santa Barbara, Linda had begun making earthenware figurines and giving them to her friends as Christmas presents. These had become so popular that she was encouraged to market them through a Christmas shop in the nearby Danish village of Solvang. When the figurines proved popular commercially as well, she and Doug began producing other types of pottery for sale in the shops of Solvang and Santa Barbara. Soon the Clayboy Pottery Company outgrew their garage workshop and they began renting a small storefront shop in Santa Barbara. A second shop was added next door when it became available three years later.

Growth: In the last 15 years pottery figurines of many types have enjoyed a rapid increase in popularity and at the same time many new firms have entered the market. For the most part, competition was rather localized and consisted mainly of small companies like Clayboy. However, a few larger and broader-based companies had also entered, increasing both consumers' choices and the price competition.
As the end of its tenth year approached, Clayboy had experienced a relatively uninterrupted period of growth-in sales, personnel and profits. For future growth and profitability, though, the Rices felt that it was time to move into a larger, more efficient building, one that was designed especially for their business.

The new facility: In preparation for the big move, Linda and Doug removed themselves from much of the daily running of the company in order to do some planning and analysis regarding the new facility. After extensive study of the capacity needs and traffic flows between their 8 departments-Material Storage (MS), Forming (F), Glazing (G), Kilns (K), Specialty (S), Packing (P), Finished Goods (FG) and Shipping and Receiving (SR)-the Rices developed what they felt was the optimal layout for their operation. The actual construction was completed in a little under a year.

Six months after the completion of their new production and office facility, Linda and Doug Rice were feeling pretty good about their decision to rebuild. Things were finally getting organized and the new-found spaciousness was extremely welcome. Still, it had been an expensive and disruptive process and things were not running quite as efficiently as the Rices hoped they eventually would. 
The production process: Of the company's 8 departments, 5 were directly involved in production: Forming (F), Glazing (G), Kilns (K), Specialty (S) and Packing (P). All jobs began in the Forming department, where the clay was molded into the desired configuration. At this stage there was a lot of variability in the complexity of the forming and, of course, in the number of units needed. After the forming process, the jobs were sent as a whole to the Drying Kilns, where they would generally spend either one or two days eliminating the moisture from the pieces. Some jobs, however, would go to the Specialty department before drying in order to add some non-clay attachments while the pieces were still soft.

After drying, the job was sent to the glazing department. Here the pieces were coated with glaze and sent for a short time to the glazing kilns to bake on the finish. At this point larger jobs were often broken into several smaller batches in order to fit into the glazing kilns (and also to get them there as quickly as possible). Some jobs went back to glazing for a second coating (or more).

If the product required any non-clay attachments after baking, some special painting, etc., the job was sent to the Specialty department to finish up. All jobs were then sent to the Packing department, where each item was carefully wrapped and packaged to prevent breakage.

Improving the system: After designing what they thought was an optimal plant layout, Linda and Doug wanted to make sure that their facility was running as efficiently as possible. With 8 new jobs ready to go on the following Monday, Linda worked all weekend analyzing scheduling strategies and finally coming up with a schedule to get the jobs through the process as quickly as possible. She was feeling exhausted but pleased with her results. However, on their way to work on Monday, Doug interrupted her feeling of contentment.

"You know, there are lots of other areas where we have to make our operation as efficient as possible if we want to maximize our profitability-inventory control, quality control ...."

"Yeah, I know," replied Linda. "In fact, I've been concerned with the number of items returned by our customers. Besides the cost of fixing the items and shipping them back and forth, it doesn't do our reputation any good and that's what we depend on to generate sales."

"Well, most of the defects are just cosmetic and can be fixed fairly cheaply, but occasionally we have to just produce a new item from scratch," said Doug. "I figure that, on the average, it costs us an extra $40 \%$ of the item's cost, including material, labor and overhead, if we catch a defect before sending it out. The ones that are sent back by the customer cost about $100 \%$ extra."

"That's a big difference," said Linda. "Maybe we should step up our inspection efforts before sending jobs out."

Doug replied, "Well, we currently take a sample of 50 items from each job and inspect them very carefully. If we find more than one that is defective, we inspect every single item before shipping the job out and correct all the defects. Otherwise, we just go ahead and send the job out and hope that we don't get too many returned. I suppose we could inspect more of them, or perhaps change our cutoff point, but I figure that our inspectors cost us an average of $\$ 0.20$ per unit that they inspect. That can really add up, too."

"I know that the material cost of each job can vary quite a bit, but what are our current figures for labor and overhead?" Linda asked.

Doug answered, "The workers' labor costs in the various departments are not too different, actually. Including benefits, it costs us an average of $\$ 24.00$ per labor hour. Then the overhead, including such things as keeping the kilns going, is allocated at $150 \%$ of the direct labor cost."

"Do you have any feel for how many defects we typically have per job?" Linda asked.

"Not exactly," said Doug, "but I think it's probably in the range of $2 \%$ to $3 \%$ of all units."

"Hey!" Linda exclaimed. "I just had a great idea! Why don't we take this set of 8 new jobs that I just scheduled and follow them through the inspection process? We could inspect each job $100 \%$ to determine the exact number of defects that they have and then see how much it would cost us for various inspection strategies. To the extent that these are typical jobs, that could give us some insight into the best way to go in our quality control process."

"That's so crazy, it just might work!" cracked Doug. "So, let's see-we can easily simulate the costs under different sampling schemes for this particular set of jobs. We have all the time data we need from your scheduling analysis (Table 1) to calculate material, labor and overhead costs. For each strategy we can calculate the costs of sampling, the costs of repairing defects before sending out jobs and the costs of repairing defects after the customer returns them. We can change the sample size or the cutoff point, or both. I suppose we could even discard our acceptance sampling scheme entirely and try something completely different, for that matter." 
Table 1: Requirements for new jobs

\begin{tabular}{lllr}
\hline Job & Units & Sequence of requirements (min/unit) & $\begin{array}{r}\text { Material } \\
\text { cost/unit }\end{array}$ \\
\hline 1 & 200 & $3.0 \mathrm{~F}, 2$ days drying, 2.0G, .5P & $\$ 5.00$ \\
2 & 140 & $3.5 \mathrm{~F}, 1$ day drying, 1.5G, 2.0G, .5S, .5P & 6.50 \\
3 & 50 & $5.0 \mathrm{~F}, 1.5 \mathrm{~S}, 2$ days drying, 2.0G, 3.0G, 1.0P & 10.00 \\
4 & 180 & $2.0 \mathrm{~F}, 2.5 \mathrm{~S}, 1$ day drying, 3.0G, 1.0S, .5P & 7.00 \\
5 & 100 & $3.0 \mathrm{~F}, 2$ days drying, 3.0G, 1.0P & 8.00 \\
6 & 240 & 2.5F, 2 days drying, 2.0G, 2.0G, .5P & 6.00 \\
7 & 500 & 2.0F, 1.0S, 1 day drying, 1.0G, 3.0S, .5P & 5.00 \\
8 & 360 & $1.5 \mathrm{~F}, 1.0 \mathrm{~S}, 2$ days drying, $1.5 \mathrm{G}, .5 \mathrm{P}$ & 4.50 \\
\hline
\end{tabular}

Note: Setup times have been pro-rated and included in the per-unit times. Also, Glazing times include a pro-rated time for baking in the Glazing Kilns.

"Yeah," agreed Linda. "For example, why couldn't we just produce a few extra units for each job, say $1 \%$ or $2 \%$, or whatever? Then, if there were defects at the inspection stage or at the customer, we would have replacements ready to go. And they wouldn't cost any more than the original units."

"We could do that," Doug replied. "Of course, if we didn't need them to replace defects, we would have spent the money to produce them for nothing. Also, wouldn't that take a lot of storage space?"

"With our new plant I think we have a little extra space," answered Linda. "Besides, we would only keep them for a couple of months. We could put it in our contract that the customer has maybe 60 days to return defective items. Hey, we could set up a little showroom for potential customers to see our work! After 60 days we could even sell the leftovers. We could bring in tours and have them buy stuff at our shop and ...."

"Whoa, I think you're getting delusions of grandeur!" said Doug. "Let's just start by analyzing these 8 jobs and then go from there."

"OK," agreed Linda. "But since I did all the scheduling analysis, this one's your baby."

"I guess so," replied Doug, "but I'm going to need some serious caffeine. Let's stop at this Moondollars before we go in!"

\section{Points for analysis:}

- Calculate the relevant costs of the current inspection system for the 8 new jobs, including the inspection costs and the costs of repairing defects before sending jobs out and after customer returns

- Consider modifications to the acceptance sampling scheme, including different sample sizes and cutoff points and calculate the relevant costs for these jobs. Also consider other quality control strategies in place of or in addition to an acceptance sampling scheme
- Based on your analysis, what recommendations would you make regarding Clayboy's quality control strategy for all their jobs? Are there other elements of a quality program that they should consider which are not as quantifiable?

\section{RESULTS AND DISCUSSION}

Teaching notes-Clayboy Pottery Company: In analyzing this case study, students should cover the following areas:

Background and problem definition: The student is asked to boil down the basic facts of the case to a page or so in order to communicate the essence of the case to someone else. This forces the student to decide just what the most important facts are. Also, the student summarizes the symptoms pointing to the need for analysis.

Objective function: Here the student is asked to specify the main quantifiable objective function and to identify other less-quantifiable objectives. The main objective in this case is to minimize the total cost of the quality control system, including inspection costs and the costs of repairing defects. Students should write out a specific cost function. They should also consider the effect of quality on their reputation and future sales.

Missing information: This part of the report asks the student to brainstorm about what other information would be useful in the real situation. For example, in this case it would especially be nice to have a better idea of the mix of jobs that arrive over a much longer period of time. How typical are these 8 jobs that will be analyzed? Also, how much variability is there in the material, labor, overhead and inspection costs that are given? It would also be nice to have some feel for the relationship between quality and future sales.

Assumptions: In this part students are asked to identify potential weaknesses in their analysis by listing the underlying assumptions. Some of these may relate directly to the missing information, such as assuming that the various cost estimates are correct and ignoring their variability. Also, we are assuming that this small sample of jobs is representative of the company's overall mix of jobs. Other assumptions arise from the use of any quantitative model to approximate reality; here, for example, we must assume that the Poisson probability distribution gives a good approximation of the probabilities of defects observed in sampling. 
Am. J. of Economics and Business Administration 2 (1): 113-119, 2010

Analysis: This is the heart of the case study, where the student is guided by the Points for Analysis provided in the case. The main result of the case is a recommended method of statistical quality control for outgoing jobs. The current system is an acceptance sampling process where a sample of 50 items is inspected from each batch and the batch is accepted if 1 or fewer defects are found in the sample. After calculating the inspection cost and cost of repairing defects under the current system, students should try variations of the sample size and cutoff point in the acceptance sampling process.

Table 3 shows the calculations of material, labor and overhead costs based on costs given in the case and in Table 1 and 2. The last two columns show the cost per unit of fixing a defect at the plant and of fixing a defect that is returned by the consumer.

Table 2: Defects found per job

\begin{tabular}{lcc}
\hline Job & Units & Defects \\
\hline 1 & 200 & 3 \\
2 & 140 & 3 \\
3 & 50 & 1 \\
4 & 180 & 4 \\
5 & 100 & 3 \\
6 & 240 & 6 \\
7 & 500 & 12 \\
8 & 360 & 12 \\
\hline
\end{tabular}

Table 3: Cost calculations

\begin{tabular}{|c|c|c|c|c|c|c|c|c|c|}
\hline Job & Units & $\begin{array}{l}\text { Material } \\
\text { cost/unit (\$) }\end{array}$ & $\begin{array}{l}\text { Total } \\
\text { material (\$) }\end{array}$ & $\begin{array}{l}\text { Total } \\
\text { labor }(\$)\end{array}$ & $\begin{array}{l}\text { Labor } \\
\text { cost/unit (\$) }\end{array}$ & $\begin{array}{l}\text { Overhead } \\
\text { cost/unit (\$) }\end{array}$ & $\begin{array}{l}\text { Total } \\
\text { cost/unit } \\
(\$)\end{array}$ & $\begin{array}{l}\text { Plant } \\
\text { defect } \\
\text { cost/unit (\$) }\end{array}$ & $\begin{array}{l}\text { Consumer } \\
\text { defect } \\
\text { cost/unit (\$) }\end{array}$ \\
\hline 1 & 200 & 5.00 & 1,000 & 440 & 2.20 & 3.30 & 10.50 & 4.20 & 10.50 \\
\hline 2 & 140 & 6.50 & 910 & 448 & 3.20 & 4.80 & 14.50 & 5.80 & 14.50 \\
\hline 3 & 50 & 10.00 & 500 & 250 & 5.00 & 7.50 & 22.50 & 9.00 & 22.50 \\
\hline 4 & 180 & 7.00 & 1,260 & 648 & 3.60 & 5.40 & 16.00 & 6.40 & 16.00 \\
\hline 5 & 100 & 8.00 & 800 & 280 & 2.80 & 4.20 & 15.00 & 6.00 & 15.00 \\
\hline 6 & 240 & 6.00 & 1,440 & 672 & 2.80 & 4.20 & 13.00 & 5.20 & 13.00 \\
\hline 7 & 500 & 5.00 & 2,500 & 1,500 & 3.00 & 4.50 & 12.50 & 5.00 & 12.50 \\
\hline 8 & 360 & 4.50 & 1,620 & 648 & 1.80 & 2.70 & 9.00 & 3.60 & 9.00 \\
\hline
\end{tabular}

Table 4: Probability calculations

\begin{tabular}{|c|c|c|c|c|c|c|c|c|c|}
\hline Job & Units & Defects & $\mathrm{P}$ & $\mathrm{nP}$ & $\mathrm{P}(0)$ & $\mathrm{P}(1)$ & $\mathrm{P}(2+)$ & & \\
\hline \multicolumn{10}{|c|}{$\mathrm{n}=50, \mathrm{c}=1$} \\
\hline 1 & 200 & 3 & 0.0150 & 0.7500 & 0.4724 & 0.3543 & 0.1734 & & \\
\hline 2 & 140 & 3 & 0.0214 & 1.0714 & 0.3425 & 0.3670 & 0.2905 & & \\
\hline 3 & 50 & 1 & 0.0200 & 1.0000 & 0.3679 & 0.3679 & 0.2642 & & \\
\hline 4 & 180 & 4 & 0.0222 & 1.1111 & 0.3292 & 0.3658 & 0.3050 & & \\
\hline 5 & 100 & 3 & 0.0300 & 1.5000 & 0.2231 & 0.3347 & 0.4422 & & \\
\hline 6 & 240 & 6 & 0.0250 & 1.2500 & 0.2865 & 0.3581 & 0.3554 & & \\
\hline 7 & 500 & 12 & 0.0240 & 1.2000 & 0.3012 & 0.3614 & 0.3374 & & \\
\hline 8 & 360 & 12 & 0.0333 & 1.6667 & 0.1889 & 0.3148 & 0.4963 & & \\
\hline Job & Units & Defects & $\mathrm{P}$ & $\mathrm{nP}$ & $\mathrm{P}(0)$ & $\mathrm{P}(1)$ & $\mathrm{P}(2)$ & $\mathrm{P}(3)$ & $\mathrm{P}(4+)$ \\
\hline \multicolumn{10}{|c|}{$\mathrm{n}=100, \mathrm{c}=3$} \\
\hline 1 & 200 & 3 & 0.0150 & 1.5000 & 0.2231 & 0.3347 & 0.2510 & 0.1255 & 0.0656 \\
\hline 2 & 140 & 3 & 0.0214 & 2.1429 & 0.1173 & 0.2514 & 0.2694 & 0.1924 & 0.1695 \\
\hline 3 & 50 & 1 & 0.0200 & 2.0000 & 0.1353 & 0.2707 & 0.2707 & 0.1804 & 0.1429 \\
\hline 4 & 180 & 4 & 0.0222 & 2.2222 & 0.1084 & 0.2408 & 0.2676 & 0.1982 & 0.1850 \\
\hline 5 & 100 & 3 & 0.0300 & 3.0000 & 0.0498 & 0.1494 & 0.2240 & 0.2240 & 0.3528 \\
\hline 6 & 240 & 6 & 0.0250 & 2.5000 & 0.0821 & 0.2052 & 0.2565 & 0.2138 & 0.2424 \\
\hline 7 & 500 & 12 & 0.0240 & 2.4000 & 0.0907 & 0.2177 & 0.2613 & 0.2090 & 0.2213 \\
\hline 8 & 360 & 12 & 0.0333 & 3.3333 & 0.0357 & 0.1189 & 0.1982 & 0.2202 & 0.4270 \\
\hline Job & Units & Defects & $\mathrm{P}$ & $\mathrm{nP}$ & $\mathrm{P}(0)$ & $\mathrm{P}(1)$ & $\mathrm{P}(2)$ & $\mathrm{P}(3+)$ & \\
\hline \multicolumn{10}{|c|}{$\mathrm{n}=150, \mathrm{c}=2$} \\
\hline 1 & 200 & 3 & 0.0150 & 2.2500 & 0.1054 & 0.2371 & 0.2668 & 0.3907 & \\
\hline 2 & 140 & 3 & 0.0214 & 3.2143 & 0.0402 & 0.1292 & 0.2076 & 0.6231 & \\
\hline 3 & 50 & 1 & 0.0200 & 3.0000 & 0.0498 & 0.1494 & 0.2240 & 0.5768 & \\
\hline 4 & 180 & 4 & 0.0222 & 3.3333 & 0.0357 & 0.1189 & 0.1982 & 0.6472 & \\
\hline 5 & 100 & 3 & 0.0300 & 4.5000 & 0.0111 & 0.0500 & 0.1125 & 0.8264 & \\
\hline 6 & 240 & 6 & 0.0250 & 3.7500 & 0.0235 & 0.0882 & 0.1654 & 0.7229 & \\
\hline 7 & 500 & 12 & 0.0240 & 3.6000 & 0.0273 & 0.0984 & 0.1771 & 0.6973 & \\
\hline 8 & 360 & 12 & 0.0333 & 5.0000 & 0.0067 & 0.0337 & 0.0842 & 0.8753 & \\
\hline
\end{tabular}


In Table 4 probabilities are calculated for observing various numbers of defects in the sample using the current system and two alternative systems with different sample sizes and cutoff points. The Poisson probability distribution is commonly used to approximate these probabilities, although the hypergeometric distribution will provide the actual probabilities if students are familiar with it. The righthand column shows the probability of rejecting the batch in each case (finding more defects in the sample than the given cutoff number).

Using these probabilities, the expected costs of sampling and repairing defects are found in Table 5 for each of the three alternatives. In several cases the sample size being used is equal to or greater than the batch size; in such cases the exact number of defects in the batch is determined and there is no need for an accept-or-reject decision since the batch has already been inspected $100 \%$.

Table 5: Total expected costs

Defects in sample

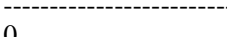

0

$\mathrm{n}=50, \mathrm{c}=1$

Job 1

Probability

Plant cost (\$)

Consumer cost $(\$)$

Inspection cost (\$)

Total cost $(\$)$

Job 2

Probability

Plant cost (\$)

Consumer cost $(\$)$

Inspection cost (\$)

Total cost (\$)

Job 3

Probability

Plant cost (\$)

Consumer cost $(\$)$

Inspection cost $(\$)$

Total cost $(\$)$

Job 4

Probability

Plant cost (\$)

Consumer cost $(\$)$

Inspection cost (\$)

Total cost (\$)

Job 5

Probability

Plant cost $(\$)$

Consumer cost $(\$)$

Inspection cost (\$)

Total cost $(\$)$

Job 6

Probability

Plant cost (\$)

Consumer cost $(\$)$

Inspection cost (\$)

Total cost $(\$)$

Job 7

Probability

Plant cost (\$)

Consumer cost $(\$)$

Inspection cost $(\$)$

Total cost (\$)

Job 8

Probability

Plant cost (\$)

Consumer cost $(\$)$

Inspection cost (\$)

Total cost (\$)

$\underline{\text { Total expected cost of all jobs }}$

0.0000

0.0000

22.5000

10.0000

32.5000

0.3292

0.0000

64.0000

10.0000

74.0000

0.2231

0.0000

45.0000

10.0000

55.0000
1

$2+$

Expected

cost

41.19

$\begin{array}{lll}10.0000 & 10.0000 & 40.0000 \\ 41.5000 & 35.2000 & 52.6000\end{array}$

$\begin{array}{lll}0.3425 & 0.3670 & 0.2905\end{array}$

$\begin{array}{lll}0.0000 & 5.8000 & 17.4000\end{array}$

$\begin{array}{lll}43.5000 & 29.0000 & 0.0000\end{array}$

$\begin{array}{lll}10.0000 & 10.0000 & 28.0000\end{array}$

$\begin{array}{lll}53.5000 & 44.8000 & 45.4000\end{array}$

47.95

1.0000

9.0000

0.0000

10.0000

19.0000

19.00

0.3658

6.4000

48.0000

10.0000

64.4000

0.0000

9.0000

0.0000

10.0000

19.0000

0.3050

25.6000

0.0000

36.0000

61.6000

66.71

0.4422

18.0000

0.0000

20.0000

38.0000

44.47

0.3554

31.2000

0.0000

48.0000

79.2000

82.08

0.3374

60.0000

0.0000

100.0000

160.0000

157.29

0.4963

43.2000

0.0000

72.0000

115.2000

114.91

573.60 
Am. J. of Economics and Business Administration 2 (1): 113-119, 2010

Table 5: Continued

\begin{tabular}{|c|c|c|c|c|c|c|}
\hline & \multicolumn{5}{|c|}{ Defects in sample } & \\
\hline & 0 & 1 & 2 & 3 & $4+$ & \\
\hline \multicolumn{7}{|l|}{$\mathrm{n}=100, \mathrm{c}=3$} \\
\hline Probability & 0.2231 & 0.3347 & 0.2510 & 0.1255 & 0.0656 & \\
\hline Plant cost (\$) & 0.0000 & 4.2000 & 8.4000 & 12.6000 & 12.6000 & \\
\hline Consumer cost (\$) & 31.5000 & 21.0000 & 10.5000 & 0.0000 & 0.0000 & \\
\hline Inspection cost (\$) & 20.0000 & 20.0000 & 20.0000 & 20.0000 & 40.0000 & \\
\hline Total cost $(\$)$ & 51.5000 & 45.2000 & 38.9000 & 32.6000 & 52.6000 & 43.93 \\
\hline \multicolumn{7}{|l|}{ Job 2} \\
\hline Probability & 0.1173 & 0.2514 & 0.2694 & 0.1924 & 0.1695 & \\
\hline Plant cost (\$) & 0.0000 & 5.8000 & 11.6000 & 17.4000 & 17.4000 & \\
\hline Consumer cost (\$) & 43.5000 & 29.0000 & 14.5000 & 0.0000 & 0.0000 & \\
\hline Inspection cost (\$) & 20.0000 & 20.0000 & 20.0000 & 20.0000 & 28.0000 & \\
\hline Total cost (\$) & 63.5000 & 54.8000 & 46.1000 & 37.4000 & 45.4000 & 48.54 \\
\hline \multicolumn{7}{|l|}{ Job 3} \\
\hline Probability & 0.0000 & 1.0000 & 0.0000 & 0.0000 & 0.0000 & \\
\hline Plant cost (\$) & 0.0000 & 9.0000 & 0.0000 & 0.0000 & 0.0000 & \\
\hline Consumer cost (\$) & 22.5000 & 0.0000 & 0.0000 & 0.0000 & 0.0000 & \\
\hline Inspection cost (\$) & 10.0000 & 10.0000 & 10.0000 & 10.0000 & 10.0000 & \\
\hline Total cost $(\$)$ & 32.5000 & 19.0000 & 10.0000 & 10.0000 & 10.0000 & 19.00 \\
\hline \multicolumn{7}{|l|}{ Job 4} \\
\hline Probability & 0.1084 & 0.2408 & 0.2676 & 0.1982 & 0.1850 & \\
\hline Plant cost $(\$)$ & 0.0000 & 6.4000 & 12.8000 & 19.2000 & 25.6000 & \\
\hline Consumer cost (\$) & 64.0000 & 48.0000 & 32.0000 & 16.0000 & 0.0000 & \\
\hline Inspection cost (\$) & 20.0000 & 20.0000 & 20.0000 & 20.0000 & 36.0000 & \\
\hline Total cost (\$) & 84.0000 & 74.4000 & 64.8000 & 55.2000 & 61.6000 & 66.70 \\
\hline \multicolumn{7}{|l|}{ Job 5} \\
\hline Probability & 0.0000 & 0.0000 & 0.0000 & 1.0000 & 0.0000 & \\
\hline Plant cost $(\$)$ & 0.0000 & 6.0000 & 12.0000 & 18.0000 & 18.0000 & \\
\hline Consumer cost (\$) & 45.0000 & 30.0000 & 15.0000 & 0.0000 & 0.0000 & \\
\hline Inspection cost (\$) & 20.0000 & 20.0000 & 20.0000 & 20.0000 & 20.0000 & \\
\hline Total cost (\$) & 65.0000 & 56.0000 & 47.0000 & 38.0000 & 38.0000 & 38.00 \\
\hline \multicolumn{7}{|l|}{ Job 6} \\
\hline Probability & 0.0821 & 0.2052 & 0.2565 & 0.2138 & 0.2424 & \\
\hline Plant cost $(\$)$ & 0.0000 & 5.2000 & 10.4000 & 15.6000 & 31.2000 & \\
\hline Consumer cost (\$) & 78.0000 & 65.0000 & 52.0000 & 39.0000 & 0.0000 & \\
\hline Inspection cost (\$) & 20.0000 & 20.0000 & 20.0000 & 20.0000 & 48.0000 & \\
\hline Total cost $(\$)$ & 98.0000 & 90.2000 & 82.4000 & 74.6000 & 79.2000 & 82.84 \\
\hline \multicolumn{7}{|l|}{ Job 7} \\
\hline Probability & 0.0907 & 0.2177 & 0.2613 & 0.2090 & 0.2213 & \\
\hline Plant cost (\$) & 0.0000 & 5.0000 & 10.0000 & 15.0000 & 60.0000 & \\
\hline Consumer cost (\$) & 150.0000 & 137.5000 & 125.0000 & 112.5000 & 0.0000 & \\
\hline Inspection cost (\$) & 20.0000 & 20.0000 & 20.0000 & 20.0000 & 100.0000 & \\
\hline Total cost $(\$)$ & 170.0000 & 162.5000 & 155.0000 & 147.5000 & 160.0000 & 157.53 \\
\hline \multicolumn{7}{|l|}{ Job 8} \\
\hline Probability & 0.0357 & 0.1189 & 0.1982 & 0.2202 & 0.4270 & \\
\hline Plant cost $(\$)$ & 0.0000 & 3.6000 & 7.2000 & 10.8000 & 43.2000 & \\
\hline Consumer cost (\$) & 108.0000 & 99.0000 & 90.0000 & 81.0000 & 0.0000 & \\
\hline Inspection cost (\$) & 20.0000 & 20.0000 & 20.0000 & 20.0000 & 72.0000 & \\
\hline Total cost $(\$)$ & 128.0000 & 122.6000 & 117.2000 & 111.8000 & 115.2000 & 116.18 \\
\hline \multirow[t]{3}{*}{ Total expected cos } & & & & & & 572.72 \\
\hline & \multicolumn{4}{|c|}{ Defects in sample } & & \\
\hline & 0 & 1 & 2 & $3+$ & & \\
\hline \multicolumn{7}{|l|}{$\begin{array}{l}\mathrm{n}=150, \mathrm{c}=2 \\
\text { Job } 1\end{array}$} \\
\hline Probability & 0.1054 & 0.2371 & 0.2668 & 0.3907 & & \\
\hline Plant cost (\$) & 0.0000 & 4.2000 & 8.4000 & 12.6000 & & \\
\hline Consumer cost (\$) & 31.5000 & 21.0000 & 10.5000 & 0.0000 & & \\
\hline Inspection cost (\$) & 30.0000 & 30.0000 & 30.0000 & 40.0000 & & \\
\hline Total cost $(\$)$ & 61.5000 & 55.2000 & 48.9000 & 52.6000 & & 53.17 \\
\hline Job 2 & & & & & & \\
\hline Probability & 0.0000 & 0.0000 & 0.0000 & 1.0000 & & \\
\hline Plant cost $(\$)$ & 0.0000 & 5.8000 & 11.6000 & 17.4000 & & \\
\hline Consumer cost (\$) & 43.5000 & 29.0000 & 14.5000 & 0.0000 & & \\
\hline Inspection cost (\$) & 28.0000 & 28.0000 & 28.0000 & 28.0000 & & \\
\hline Total cost (\$) & 71.5000 & 62.8000 & 54.1000 & 45.4000 & & 45.40 \\
\hline
\end{tabular}


Am. J. of Economics and Business Administration 2 (1): 113-119, 2010

Table 5: Continued

Job 3

Probability

Plant cost $(\$)$

Consumer cost $(\$)$

Inspection cost (\$)

Total cost (\$)

Job 4

Probability

Plant cost (\$)

Consumer cost $(\$)$

Inspection cost $(\$)$

Total cost (\$)

Job 5

Probability

Plant cost (\$)

Consumer cost $(\$)$

Inspection cost (\$)

Total cost (\$)

Job 6

Probability

Plant cost $(\$)$

Consumer cost $(\$)$

Inspection cost $(\$)$

Total cost (\$)

Job 7

Probability

Plant cost (\$)

Consumer cost (\$)

Inspection cost (\$)

Total cost $(\$)$

Job 8

Probability

Plant cost (\$)

Consumer cost (\$)

Inspection cost (\$)

Total cost $(\$)$

Total expected cost of all jobs

0.0000
0.0000
22.5000
10.0000
32.5000

0.0357
0.0000
64.0000
30.0000
94.0000

0.0000
0.0000
45.0000
20.0000
65.0000

0.0235
0.0000
78.0000
30.0000
108.0000

0.0273
0.0000
150.0000
30.0000
180.0000

0.0067
0.0000
108.0000
30.0000
138.0000

1.0000
9.0000
0.0000
10.0000
19.0000

0.1189
6.4000
48.0000
30.0000
84.4000

0.0000
6.0000
30.0000
20.0000
56.0000

0.0882
5.2000
65.0000
30.0000
100.2000

0.0984
5.0000
137.5000
30.0000
172.5000

0.0337
3.6000
99.0000
30.0000
132.6000

132.6000
0.0000

0.0000

$0.0000 \quad 0.0000$

$10.0000 \quad 10.0000$

$10.0000 \quad 10.0000$

$0.1982 \quad 0.6472$

$12.8000 \quad 25.6000$

$32.0000 \quad 0.0000$

$30.0000 \quad 36.0000$

$74.8000 \quad 61.6000$

$0.0000 \quad 1.0000$

$12.0000 \quad 18.0000$

$15.0000 \quad 0.0000$

$20.0000 \quad 20.0000$

$47.0000 \quad 38.0000$

$0.1654 \quad 0.7229$

$10.4000 \quad 31.2000$

$52.0000 \quad 0.0000$

$30.0000 \quad 48.0000$

$92.4000 \quad 79.2000$

$0.1771 \quad 0.6973$

$10.0000 \quad 60.0000$

$125.0000 \quad 0.0000$
30.0000

$30.0000 \quad 100.0000$

$\begin{array}{rr}165.0000 & 160.0000\end{array}$

$0.0842 \quad 0.8753$

$7.2000 \quad 43.2000$

$90.0000 \quad 0.0000$

$30.0000 \quad 72.0000$

$127.2000 \quad 115.2000$
19.00

68.08

38.00

83.91

162.66

116.95
Of the three alternatives examined, the cheapest (by less than $\$ 1.00$ !) for these 8 jobs would have been to use a sample size of 100 and a cutoff point of 3 . Students could continue to fine-tune their sample size and cutoff point to obtain the cheapest sampling scheme.

One extreme solution would be to discontinue sampling any of the items and simply to send them out to the customer. Costs would be just the cost of defects returned from the consumers. These can be found in Table 5 under "Consumer Cost" and 0 defects in the sample. The total of these for the eight jobs is $\$ 542.50$, which is significantly cheaper than the alternatives using acceptance sampling. However, the student should recognize that there is a nonquantitative cost in the dissatisfaction of the customers and the resulting effect on future sales.

The opposite extreme would be to inspect all jobs $100 \%$ before sending them out and repairing defects at the cheaper plant rate. These costs can be found in Table 5 in the "Total Cost" row in the right-hand column of defects. The total of these costs is $\$ 571.00$, slightly cheaper than the best of the three alternatives examined so far and certainly better for the company's reputation.
Students may also try other creative alternatives, such as producing a few extra units to substitute for defects, as mentioned in the case.

\section{CONCLUSION}

After their analysis students can summarize the results of the analysis, along with any cautions regarding the solution and any suggestions regarding implementation. This is another opportunity for the student to show an understanding of the realities of the situation as well as the quantitative analysis. For example, in this case students should express caution regarding their results because of the assumptions made about costs and probabilities and especially because of the small sample of jobs examined. They should also discuss some of the nonquantitative ramifications of their alternatives before coming up with their recommended alternative and they should show awareness of the need for further study and monitoring in the future. 